\title{
Using conjoint interviews with couples that have been living with disabilities and illnesses for a long time - implications and insights
}

\author{
Cristina Joy Torgé
}

\begin{abstract}
This article discusses conjoint interviews and takes its starting point from a study with nine older couples who have been living with disabilities for a long period of time. Conjoint interviewing where dyads are interviewed together produces a different kind of data from individual interviews specifically data that conduce different ways of talking about "we-ness" and produce interaction between the participants. This article discusses how this appeared in a study that was interested in the understandings and actualizations of spousal care when both have a disability or illness. The method leads to an analysis centered on mutuality and has potential to problematize traditional caring tasks and caring roles in the context of living with disability or chronic illness. Potentials and limitations of the method are discussed.
\end{abstract}

Keywords: couples, conjoint interviews, dyadic methods, spousal care, disability

Please cite this article as:

Torgé, C. J. (2013). Using conjoint interviews with couples that have been living with disabilities and illnesses for a long time - implications and insights. Qualitative Studies, 4(2): 100-113.

\section{Introduction}

Individual interviews are still somewhat taken as the norm in the social sciences. This is illustrated metaphorically in Kvale and Brinkmann's well-cited textbook on qualitative interview research through Rubin's image of figure/ground (representing the interaction between the interviewer and the interviewed, and the meaning created between them). The interview is also defined as "literally an inter view, an inter-change of views between two persons conversing about a theme of mutual interest" (Kvale \& Brinkmann, 2009, p. 2). Consequently, even relational phenomena such as love or cooperation are studied from a collection of individual views (Kenny et al., 2006). But what kind of data, and what other kinds of knowledge can arise when study designs presuppose mutuality? There is a need to reflect the mutual dimensions of relationships more directly in research, through using interview methods that are also inherently relational, such as dyadic interviewing of couples (Eisikovits \& Koren, 2010).

This article focuses on dyadic interviews, as a method directed at specific types of relations, and which produces data of certain characteristics. The discussion takes its starting point from a conjoint interview study on spousal help and support made with partners who had both been living with disability and illness for a long period of time. The article's aim is two-fold: it aims to discuss the kind of data produced in these conjoint interviews, but it also aims to explore how the resulting dyadic data can provide insights on spousal care and support in a disability context. There are three questions to discuss: What are the characteristics of the data generated in these conjoint interviews? How can the resulting data contribute to understanding care in disability contexts? And what are the potentials and limitations of the method?

I begin by describing how dyadic interviewing is increasingly being used in the field of health and illness research - especially regarding spousal care. This is followed by examples from my own data of how conjoint interviews shaped stories centered on relationality. "We-ness" and "we-talk" emerged in the interviews, but these are also results that help one understand the couples' perspective on mutual spousal 
caring. The interview data were also interactive and performative, which gave insights into the possibilities and difficulties in caring with disabilities. By showing how the data shape analysis, this article shows how conjoint interviewing and the resulting dyadic data are useful for generating further insights regarding informal care in disability contexts.

\section{Dyadic interviews}

Dyadic interviews have been discussed as a potential alternative to individual interviews for the last 30-40 years, both in social sciences and family research (Allan, 1980; Bennet \& McAvity, 1994; Arskey, 1996). It has been used to study different pair relations, such as couples, best friends, siblings, parents and children, or even co-workers (some examples: Mauthner, 2000; Rosenblum, 2000). Like focus groups that have not been used in early social science research, dyadic interviews have not been widely used until recent years although it was an established interview method in therapeutic contexts (Bennet \& McAvity, 1994; Morris, 2001). Until today, interviewing dyads may still often be met with negative attitudes and skepticism, possibly because of the dominance of atomistic views of the self (Bjørnholt \& Farstad, 2012).

Dyadic interviews are directed at specific types of relations. A condition for a group to be called a dyad is the experience of a "we' relationship", formed through having shared time and space together (Eisikovitz \& Koren, 2010). The pre-existing relationship between the interviewed dyad is thus, rather than a contingency, a premise in the dyadic interview. Compared to focus groups that usually rely on 'ad hoc' groups of people that might not previously know each other (Morgan, 1996; Hydén \& Bülow, 2003), dyadic interviewing is directed at naturally occurring pairs. As with focus groups, the topic of the interview is determined by the researcher. However, rather than keeping a moderator role, the interviewer asks questions directed at the dyad, as individuals or as a pair. This allows the researcher to gain insight into the dyad's construction of a "concurrent framework", at the same time that the participants can "represent themselves not just as individuals but also as concurrent participants in a relationship" (Morris, 2001, p. 558). In other words, the researcher can capture individual views as well as shared perceptions of common experiences, for example regarding family life and family history (Bennet \& McAvity, 1994). This contributes another difference to focus groups, as the pre-existing relationship takes on an added layer of significance in the dyadic interview situation through the researcher's aim to understand the dyad's "joint" view.

Dyads can be interviewed together, separately but simultaneously, or separately at different occasions (Eisikovits \& Koren, 2010). Dyadic interviewing can also be used in combination with other data collection forms (Arskey, 1996). Generally, however, when the interview method is named, the term "dyadic interview" seems to refer to any interview method involving dyads as the unit of data collection and analysis, whereas "conjoint interviews" (or sometimes "joint interviews") are those in which the dyad is interviewed simultaneously in the same interview situation. The conjoint interview is also what was used in the study at hand.

Reviews of the literature show that individual perspectives still tend to be the norm, but that there is nevertheless a growing interest in exploring dyadic perspectives (Braun et al., 2009; Walker \& Luszcz, 2009). It is also possible that other studies employ dyadic interview methods but do not use the terms "dyadic interview", "joint interview" or "couple interview" to describe their methods.

\section{Couplehood in disability and illness}

The usefulness of dyadic interviewing seems to be reflected in the growing number of studies using dyadic designs in the substantive field of health research, specifically on partners' or spouses' experiences of illness in the family. Different kinds and combinations of dyadic interviewing have been used to 
understand the impact of living and coping with illness when a partner or spouse acquires physical or cognitive impairments (e.g. Clipp \& George, 1992; Schumacher, 1996; Jo et al., 2007; Morris, 2001).

Within the fields of aging, disability and care, there is much recent literature whose results build on dyadic interviews. Examples of such studies are those conducted by Yorgason et al. $(2007,2010)$ on older couples living with various impairments; by van Nes, Runge and Jonsson (2009) on an older couple's intertwined occupational patterns after stroke; by Soodeen, Gregory and Bond (2007) on older spouses where one qualifies for home care; and by Cahill et al. (2009) on care burden using interviews with older people together with their spouse or adult child carers. Dyadic interviews with older couples could also be about access to health-related services when aging in place (Racher, 2003) or their patterns of mutual caring as they acquire disabilities and live without children (Ahn \& Kim, 2007). Literature on older spouses and spousal care are also gaining ground in the context of couplehood in dementia, where the views of both the spouse and person with dementia can be explored (e.g. McGovern, 2011; Molyneaux et al., 2011; Hellström, Nolan \& Lundh, 2005a, 2005b).

The starting point of these studies is that the experience of disability or illness does not only affect the individuals in question, but also affect their intimate partners in terms of relationship and communication issues, help-seeking behavior, practical consequences in everyday life and planning for the future. Some of these studies note how literature on disability, spousal care and aging - like much of qualitative interview research in general - often are constructed from the perspective of one partner alone, leading to health services directed at individual caregivers or their care recipients, instead of looking at the couple's common need for support (Racher, 2003; Braun et al., 2009; Ahn \& Kim, 2007). The perspective of the family unit, the complexity of family caregiving and how families produce joint accounts of illness, they argue, are obscured in studies based on individual interviews - something that might be counterbalanced through using specifically dyadic approaches to research.

\section{Description of the study and participants}

This article takes its starting point from a study with nine older couples, 60 years or older at the time of the interview, where both partners had lived with disability and/or chronic illness for a long period of time. The aim of the study was to find out how couples that had both been living with disabilities describe and exchange spousal help and support. As the participants were ageing together with disabilities, another ambition of the study was also to find out - retrospectively from the couples' perspectives - how changes in help-giving looked like when both partners' needs and capacities change with disability trajectory and time.

The participating couples, married or co-habiting, were mostly recruited through an information letter that was distributed to various disability organizations in southeastern Sweden, as well as through snowball sampling. An information letter described the purpose of the study and informed that the interviews were to be made conjointly. One couple with visual impairments had to be informed about the research through telephone. The couples interested in participating then had the choice to contact the researcher themselves or express a wish to be contacted. The study fulfills thereby the research ethics criteria of informed consent. The initial choice of conjoint interviewing was also made from an ethical consideration that it would be difficult to make partners anonymous for each other in the written study, especially if a small group of people were interviewed. A third ethical consideration was only couples with physical (and not cognitive) disabilities were asked to participate. Names of persons have been changed in the writing of the study. 
Previous research on spousal care have often been based on identifications of being either a "carer" or "spouse with disability", even though it might be possible that both partners have impairments or illnesses (see e.g. Parker, 1993; Ahn \& Kim, 2007). In the study in question, the individual roles as caregiver and care receiver were not pre-determined or self-evident, as both had long-term disabilities. The participants varied with regard to types of disabilities or illnesses and when these were acquired. Examples are cerebral palsy (CP), blindness, hearing impairments, multiple sclerosis (MS) and polio. Others had genetic or neurological conditions, and some suffered illnesses in youth or middle-age that had led to disablement. The participants also received or were entitled to different kinds of formal support such as home help, help with cleaning, transport services, assistance for the blind, loan of technical aids or personal assistance. The accessibility of formal help in the welfare system is an important socio-historical context, as this shaped these individuals' possibilities of building families, not least with partners that also have disabilities and/or illnesses. The existing disability policies in the Swedish welfare system also serve as a frame through which we can appreciate the voluntary help-giving within families and informal circles that continue to take place and make up indispensable support for people with disabilities (see Jeppsson Grassman, Whitaker \& Taghizadeh Larsson, 2009).

In interviews, the couples were asked about the effects of disability on their everyday lives, their help needs and sources of help, mutual caring, and their views about the practical implications of ageing together with sometimes severe or worsening physical disabilities. An interview guide was used as a tool to cover themes of interest. However, the couples could also talk freely about related themes. The interviews were transcribed and then coded and compared. In this current article only a few codes, which seemed to have resulted from the interview method, are discussed. Empirical results on how to understand help-giving between the couples is discussed elsewhere (Torgé, 2013). The focus of the following discussion is how the conjoint interviews influenced the kind of data produced, and the possibilities and limitations of the dyadic data in understanding spousal care with disabilities.

\section{"We-ness" as an interview effect and result}

What kind of data is generated in the conjoint interviews? It is obvious from first glance that the conjoint interviews produced another kind of conversation than if individual interviews were used. In terms of language, the most obvious indication of this interaction is the use of "us", "we" and "you" (referring to me as the interviewer). Most couples were also interviewed in their own homes, adding to their sense of being a unit consisting of two individual members - a sense "of being two" (in the words of a participant), or what seems to be a sense of we-ness.

In reflecting on this "we-ness" or presentation of themselves as a unit, it soon became clear that their narratives of being a unit were as much shaped by the interview situation and the research focus on mutuality, as they were shaped by the couples themselves and how they voiced their story. What was created was not only a conversation about a topic (caring and ageing as a couple with disabilities); the interview setting also encouraged a certain form of interaction to take place, which reinforced the sense of couplehood as a "we".

When couples talked about themselves, "we-talk" not only underlined the pre-existing relationship as a fact but also produced stories about "our experiences" (see Seale et al., 2008). Included in the verbal presentation of "we-ness" are common experiences and endeavors - including practical considerations of both of them living with disabilities or chronic illnesses - that have created them as a unit over time. When the couples talked about mutual help, they not only retold concrete examples in their everyday lives but also used phrases such as "fighting our unique - but similar - illnesses together" or "the right 
hand helping the left". Sometimes, this presentation of "we-ness" had the effect that personal qualities became projected as an attribute of the relationship itself:

Ellen: You know, it's like this - we have always tried to fight [illness], together.

Folke: We aren't the types that give up.

Ellen: Even if I might say that 'I give up now,' I never do it. Instead, we try to battle these things that we have. It just works that way, though it doesn't work well sometimes.

"We-talk" also meant tracing their history together, which in this case was often framed by the sociohistorical context of the disability rights movement in Sweden. These and other events in their lives have historically formed the "we" from whose perspective they now speak. Disability organizations - but also self-help groups, summer camps for the disabled and special schools that have closed down long ago not only represented the physical setting of their stories, but were also used to show a common "disability identity" that stretches back for a certain time, as well as another aspect of their common endeavor. Conjoint interviewing seems appropriate in capturing these shared experiences of events lived through together, or in Eisikovitz and Koren's words (2010, p. 1643), the "dyadic being-in-the-world, in addition to the relationship component". This common history is apparent, for example, in this interview with Gert and Harriet:

Interviewer: How did you meet? Was it through the [disability organization]?

Gert: Yes, you could say that. From the beginning, since [we] were at the sanatorium. We played board games together. Ah!

Interviewer: And then you met again?

Gert: Yes, around 1951. She and I joined the [disability organization]. /.../

Harriet: But now, if you look at the local organization, it's almost just me and you that have had polio. There aren't so many left.

As mentioned above, this historical context is significant in understanding how the couples seemed to value informal help and care. It is notable, for instance, that the couples simultaneously talked about the importance of fighting for their rights to welfare services, and informal help from friends, children and each other as a regular, welcome and indispensable feature of their lives.

\section{To live "with" - and being "right in it" as resources}

When they talked about help they gave and received from each other as partners, the couples brought up concrete examples. Much of the help they gave each other was in terms of emotional support, but this too could include hands-on help such as support in making formal care arrangements, communicating with professionals on behalf of the partner, or "looking after" and protecting the partner's privacy, best interests and integrity when formal help services were involved. Notably, although many of the couples also received different kinds of formal and informal help, they also brought up many examples of helping each other with physical and instrumental tasks on a regular basis, such as helping to eat, dress, go to the toilet, and move around outside the residence.

The sense of "we-ness" also took another dimension in the interviews as it was often expressed as a resource in understanding and helping each other. Setbacks (for example, worsening health conditions), as well as triumphs (such as having been entitled to assistance) were expressed as something they experienced together and not only at an individual level. Further, the shared experience of disability was described as a resource because they saw themselves as being "right in it", thus being able to understand their partner in ways they thought others without such experiences could not. For example, the 
participants described recognizing in each other the feeling of uncertainty in the face of diagnosis ("I have been there myself") or how symptoms felt in one's body ("We know how it feels to have a fierce diabetic attack"). The participants also seemed well-read about their partners' symptoms, medications and functional limitations and saw themselves as better able to anticipate and respond to their needs.

An expression of this mutual understanding as a care resource comes from Cecilia and Danne, who had both been in previous relationships with non-disabled people. Although their past partners also used to provide help, Cecilia and Danne insisted that their shared experience of disability added another dimension for being able to anticipate and understand each other. In the interview fragment below where they compared the help they got from previous relationships, they seemed to refer to two kinds of commonalities: their commonality as both identifying as disabled people, and the sense of "we-ness" as an attribute of being a "close couple". That they also finished each other's sentences and confirmed what each other was saying also contributed to the common construction of this "we-ness" that cannot otherwise be captured if they were interviewed individually:

Cecilia: Yes, of course, but it can be difficult for a man -

Danne: - or a woman!

Cecilia: - or a woman - to live with a severely disabled partner. It's hard.

Interviewer: Why should it be easier for disabled people to do that? Why should it be easier?

Cecilia: Because we -

Danne: It's this: we are right in it. We are right in it!

Cecilia: We help each other.

Danne: We help each other, or -

Cecilia: We understand each other.

Danne: We understand, we understand. I myself know how it is. I know my own body and all that. And I know how... I mean, a healthy person can't always take himself down to that level.

Cecilia: No.

Danne: It depends. If they grew together to become...

Cecilia: A close couple.

Danne: ... a close couple.

To talk about "we-ness" as a resource then, is also to have a feeling that others outside the relationship though they may be indispensable sources of help as well - are not able to tap into that resource of a common background and common situation. This appeared in other interviews as well, for example when participants described how friends had a hard time understanding why they continued to give help despite one's own pain and tiredness.

"We-ness" and "we-talk", aside from being an interview effect, was thus also a result. The couples expressed and confirmed themselves as a unit in the different ways in the interviews - through a shared history, shared experiences, shared values and shared endeavours. Further, the sense of "we-ness" became important in trying to understand why instrumental care and help are given.

\section{Interactive and performative data}

Another characteristic of conjoint interview data is that they are interactive data. As Allan (1980) writes about joint interviews, the interaction between the participants constitutes data not easily obtainable through other methods. Interaction is obvious at the textual level, but there is also an interpersonal level of interaction (see Reissman, 1993). This was apparent in the interviews in at least two ways. First, couplehood and helping also became performative as the couples, through their interaction, gave insight on 
how it is to live together and give help when both have disabilities. Second, interaction between the partners meant that they not only could affirm each other's answers and continue each other's line of thought, but also contest, question and disagree. These interactions helped give insight to some problems that the couples faced in living and ageing together with disabilities.

As mentioned earlier, the couples talked about what they helped each other with in their everyday lives. These included activities that may traditionally be seen as informal caring tasks. But in many of the interviews, the couples not only talked about - but also performed - help-giving through interaction, through small gestures of everyday help and support. This performative aspect was no doubt facilitated by the fact that the couples were interviewed in their homes. Help-giving was thus made, even if they occurred in an interview situation, in an authentic environment where they would anyway be performed. In the course of the interview sessions, a spouse helped his partner drink from a glass and another helped his wife in blowing her nose. If a partner had a hearing or speech difficulty, the other partner helped convey the question or the answer. One couple showed me, because of their different dexterity difficulties, how only one of them could open a window but it takes the other one to close it. Another couple was keen to show me homemade household tools that that the husband produced for his wife. Another man in a wheelchair demonstrated how he fixed his wife's wheelchair after a puncture.

A different, but very striking example of this performativity was in the interview with Lucia and Krister, who had congenital disabilities. Both had mobility problems and Krister had difficulties with communication. In the interview, Lucia reminded me that Krister should have a chance to answer first because it was easy for her to take over. Soon, however, Lucia also acted as an "interpreter" to our conversation. In the interview, they not only talked about mutuality and helping in everyday life, but this was also enacted:

Lucia: Start with [Krister]. I babble all the time as it is. [Interviewer laughs]. That's what women do. But sure, if the other person has a speech difficulty... I've got to hold myself. So I don't babble through, I mean [she laughs].

Interviewer: Yes, [Krister]?

Krister: ... I was ... [slurred: disabled from birth].

Lucia: [clarifying] disabled from birth.

Krister: ... and I learned to [slurred: speak] ... when I was eight years old.

Interviewer: You learned to...?

Lucia: [clarifying] to speak.

Krister: Yes, when I was eight years old. I ... had a speech therapist for five years and as [slurred: a baby] I had ... a woman coming one hour a day ... [slurred: teaching]...

Interviewer: What did you say last?

Lucia: [clarifying] teaching.

Krister: ... me.

In terms of content, what was told in this interview fragment is the story of Krister's congenital disability and his early communication difficulties. Textually, this story was expressed despite Krister's articulation difficulties and with Lucia as an interpreter. However, it is the interactive element of the data that was most striking because it gave concrete insight into an instance of help-giving that occurred in the couple's everyday life. Lucia's comment on how easy it was for us to take over the conversation was revealing of her desire to give Krister a voice (literally and figuratively) and was an act of concern. In this way, the interview fragment could also be interpreted as a kind of balancing act between allowing independence and giving help, when a partner has more severe disabilities than oneself. In another part of the interview 
for instance, Lucia related how she wanted to protect Krister's best interests by sometimes being a mediator between him and his assistants. Although she did not want to interfere with Krister's and the assistants' professional relationship, she felt that it was in Krister's interests that she stepped up for him.

\section{Disagreements are also data}

So far, it may seem that conjoint interviews with couples only result in positive examples of "we-ness". But it is also possible that partners question each other or express different points of views. The ability to shift between the couples' jointly constructed view and individual understandings of the same events is one advantage of dyadic interviewing according to Taylor and de Vocht (2011), as this can give insight on how individual views overlap to varying degrees.

The spousal relationship involves normative and role dimensions that participants can bring into the interview situation as a couple "on stage". Intimate relations are also laden with social expectations about caring for and caring about each other as "natural" parts of the relationship, that may cast a shadow on aspects of care related to hard work, negotiation, or lack of choice. It could be argued that the interviewed couples were keen on presenting themselves in a positive light in the interviews, and may not have wanted to reveal personal opinions that might cause conflict. If this is so, this would explain the mostly concurrent and "we"-centered narratives. But although dyadic interviews could be less candid than individual ones, other researchers observe that couples in conjoint interviews do not necessarily spare each other from negative remarks and that it is uncertain if themes of disagreement would have emerged if participants had been interviewed individually (Molyneaux et al., 2011; Bjørnholt \& Farstad, 2012). Questioning each other and other expressions that things do not always go so smoothly also appeared in the study in question. These are nevertheless fertile points of analysis and can be rich sources of data on how partners give meaning to the same event in different ways (Schumacher, 1996; Beitin \& Allen, 2005).

One example of this kind spontaneous questioning in the interviews was between Ellen and Folke, as they discussed whose disability required more understanding and who understood the other best. Previous to this interview fragment, we were talking about their different disabilities and how these affected their everyday lives in a practical way. They then talked about the difficulties in understanding each other's symptoms:

Folke: [to his wife] I ... I wonder why you always say that your illness is so much worse than mine...

Interviewer: Oh.

Ellen: [giggles]

Folke: It's quite interesting. I mean, if you understand... but still experience that yours is worse than mine...

Ellen: ... Yeah. I do that.

Folke: Or is it because I spoil you? I'm nice and I get ... I get your medicine for you and never say, "Oh, go get it yourself".

Ellen: No. It's because you don't see these tremors that I have inside, inside my body.

Folke: No, I understand that it's not easy. But I can just observe that, um, a little bit like a car mechanic observes that, "Okay, the motor makes a strange noise, but it's not serious. It's going to last a few more years". End of story. But the woman who owns the car, she says, "But it's irritating, it makes such a sound!" And, in the same way, you have your tremors. Okay. Fact noted!

Interviewer: But, does it have to do with, that some aspects of the illness are invisible? That you still need to express it for it to be obvious to others? 
Ellen: [Sighs]. And [Folke] has a hard time understanding these signals...

Folke: I could be so tired and wiped out that I could drop. But even if I tell Ellen, "Just five minutes. I need to lie down for a while. I can't take it anymore", I say it in such a dry way so she doesn't even understand it. And instead you say, "Can you go fetch this and that? And can you go wash the dishes?" Like, you don't seem to understand that I feel like a catastrophe when I say "I think I'm going to pass out soon".

Both Ellen and Folke seemed to want to present themselves to me as the more understanding party by demonstrating the others' non-understanding. But as they talked, they simultaneously also had to explain to each other the difficulty of communicating their symptoms and needs. The shifting nature of disabilities could mean that help needs - but also one's capacities to help - changes over time. When symptoms, such as tiredness and fatigue, cannot be communicated, this may lead to problems when one partner's expectations do not meet the other's capacities. Help-giving requires that the other party has the ability to provide help, and this might not always be the case if one's partner also struggles with his / her disabled body. There is therefore an aspect of "timing", which is a practical consideration when two people live together with disabilities. What Ellen and Folke's interaction also suggests is that some aspects of disability are invisible, although they are concrete bodily experiences. Although disability is a shared concern within the family and a shared practical issue in everyday life, one's experience of disability thus cannot be fully shared - even with a person that one has lived with for many years. In this way, "we-ness" does not represent a complete creation of a unit. Rather, an insight from this dialogue is that the "we" is nevertheless made up of two individuals that may have, in this case, different needs and experiences of disability that they need to communicate in order to support each other. Because the subjective experience of disability and illness must first be put into words for others to understand and act on (see Kleinman, 1988), this might also pose challenges, for instance if one partner has communication difficulties.

\section{Discussion}

The aim of this article was to discuss the characteristics of data produced in conjoint interviews and to explore how dyadic data can give insights into spousal care and support in the context of disability. As the examples from the interview showed, the conjoint interviews produced a certain kind of data - one that produced stories of "we-ness" and was also interactive. But because conjoint interviewing creates data that are characteristically relational, it in turn also forces the researcher to analyze in terms of mutuality. What this article has shown is that conjoint interview data produce accounts of the couple seeing themselves as a unit, where the sense of "we-ness" plays an important role as a ground and resource of practical and emotional help-giving, even despite other help sources. In this way, the interviews captured, in a distinct way, the relational aspects of spousal caregiving. These relational aspects of care could only be understood to the full in light of the couple's shared history and experiences.

Even interaction and performativity, which permeated the interviews, contributed with unique aspects that could not have appeared if individual interviews had been chosen. The interactive elements showed how spousal help-giving could occur naturally, but also that it was not unproblematic. Even if spousal caring was actualized in many ways despite both partners' disabilities, the conjoint interviews also revealed limitations and practical issues for this help-giving, for example the aspect of "timing" and communication.

\section{Implications of conjoint interviewing}

It is of course possible, as criticized about focus group data, to analyze interactive material through showing what has been said by individuals alone (Kitzinger, 1994). However, that would not do the interactive elements justice, especially if interviewing as dyads was chosen precisely because of its 
interactive possibilities. In choosing dyadic design, "pair relatedness - variously called interdependence, reciprocity, and mutuality by researchers" (Thompson \& Walker, 1982, p. 890) also becomes an obvious focus for analysis. But besides the focus on mutuality, can data from conjoint interviews give new perspectives and knowledge?

Some examples from previous studies demonstrate how employing conjoint interviews not only produced results that centered on relationality, but also generated new perspectives. One example is a series of studies on couplehood in dementia. When they conducted separate interviews with persons with dementia and their spouses (dyadic interviews but not conjoint), Hellström, Nolan and Lundh (2005a) and Keady and Nolan (2003) already developed relational notions such as "nurturative relational context" and "working alone / together / apart". Nevertheless, in one case study where Hellström, Nolan and Lundh (2005b) interviewed a couple conjointly, "doing things together" emerged as the strongest category, leading the researchers to conclude that the notion of autonomy may sometimes be subordinate to the notion of couplehood. A second example comes from occupational therapy. Using a mix of separate and conjoint interviews, van Nes, Runge and Jonsson (2009) discussed how a couple's activities intertwined after one partner's stroke. The conjoint interviews resulted in codes such as "three hands" and "one body", where doing activities with the spouse became an extension of one's own activities in an experiential and personal way. According to the authors, this contrasted with the predominantly individual-based perspective of occupation that gave little knowledge about activities people did together, and they hoped to contribute to the theoretical development of the concept of co-occupation. These examples show how conjoint interviewing can give other perspectives than what is already known from other types of interviews, through the dyadic perspectives offered by conjoint data.

In my own study, the choice to interview the couples conjointly may also have implications for the continued discussion of spousal care in disability contexts. The importance of informal help-giving is sometimes obscured in disability research, possibly because it is thought to undermine the focus on disability rights and welfare services (Jeppsson Grassman, Whitaker \& Taghizadeh Larsson, 2009). These conjoint interviews however, showed that according to these spouses' experiences, engagement in disability rights issues and emphasizing the importance of informal help need not be contradictory. The experience of "we-ness" that emerged in the interviews were the ground for the exchange of instrumental and emotional care tasks, because of the feeling that one understood the partner best due to personal events they have been through, and through the common experience of disability or illness. Understanding the value of relationships is thus very relevant in appreciating why informal help is given and received, despite other sources of help that are aimed at increasing personal autonomy and freedom. In a way, mutual help-giving also became a way for the participants to be autonomous and free as a couple, from a life already marked with formal help.

Further, what these interviews did was show how people with disabilities could be active and voluntary givers of informal care. Though the study was on spousal help and care, one of the most significant strengths of using conjoint interviewing for this particular study was that it allowed me to make mutuality the premise of the interview, rather than pre-supposing individual roles as carers or care receivers. If individual interviews or focus groups had been used, this might have required me to frame the participants in one role or the other, consequently excluding the other partner as a possible provider of spousal help. Through conjoint interviewing, the partners could instead cast themselves in either role or both roles simultaneously. The method also allowed the participants to be described as concurrent actors in the relationship and as providers of help and care for one's partner, even if they may not be carers in the traditional sense. Even the performative aspect of the conjoint interviews showed how care could have different dimensions, which might not have appeared in individual or focus group interviews. 
The many examples of everyday helping begged the question of what actions one should call "caring" and what "naturally" occurs in a spousal relationship, since these different examples of help and support were nevertheless important in the couple's everyday lives. In this way, one could clearly see how the use of conjoint interviews not only produced unique material but also produced an analysis that can problematize traditional care discourses, include a discussion of disabled people as carers, and emphasize the relational dimensions of caring with a disability.

\section{Some considerations about the method}

Because conjoint interviews produce a certain kind of data that urges a researcher to look at it in specific ways, it is important to note not only the possibilities but the limitations of this interview method. With regards to the study, it should be remembered that the nine couples were informed about being interviewed conjointly before they agreed to participate. As in other studies where the informants themselves choose to be included, there might be a participant bias, with couples that see themselves in smooth-going relationships being more likely to participate in a conjoint interview study. If this is so, it explains the positive tone in many of the interviews. Rather than drawing too general conclusions from this study then, it is more fruitful to consider it as a contribution to an alternative discussion of spousal care - one that includes disabled people as mutual givers and receivers of informal care.

The method also has other general limitations. Criticisms of dyadic interviewing raise the issues of lack of spontaneity, disclosure of information and keeping secrets between participants. There is also reason to believe that couples are not too keen to talk about problematic or stressful issues with their partner present (see Morris, 2001; Forbat \& Henderson, 2003; Ben-Ari \& Lavee, 2007; Taylor \& de Vocht, 2011). Consequently, when studying spousal caregiving through conjoint interviews, one should be aware that aspects of spousal burden and conflicts could be underplayed. Also, despite the focus on mutuality, the researcher cannot take for granted that the partners are equal in the interview situation. One must therefore try to be sensitive to and acknowledge possible imbalances of power. This is an important point since the presence of the significant other in the interview situation need not be neutral. This is also true in the study, despite the interaction facilitating "natural" examples of help-giving in everyday life. For instance, it would not have been appropriate for Krister (who had communication problems) to take up any problems about Lucia when she had to, on many occasions, repeat verbatim what he was saying. It would also have been inappropriate for Lucia to criticize Krister, given his subordinate position in the conversation. On the other hand, echoing Heaphy and Einarsdottir (2012), the imbalance of power in their conversation could also be seen in terms of collaboration and can be explored within the context of the narrative to generate insights, rather than seeing the interaction as a problem to be solved.

Another important point to consider with this method is what may be thought of as a circular logic between data generation and interpretation. That is, when one explicitly asks a couple about mutual care and support, stories of "we-ness" tend to emerge which in turn encourages interpretations about mutuality. The relationship between data and interpretation is explicit with this method, but actually defines all qualitative research. As Reissman (1993) maintains, interview methods shape the narrative form and, in turn, the researcher's story about what the narratives might signify. Nevertheless, though the data and its possible interpretations are of a certain nature, this need not be a disadvantage for the emerging results. Dyadic data, through its unique characteristics, also generates other insights as a consequence, as was pointed out in previous examples. One could also look at the data produced as specific narratives about mutual care that emerge from a different starting point or premise than individual interviews. This means, consequently, that conjoint interviewing may be less suitable for studying other dimensions of caregiving. Individual interviews or focus groups with carers or spouses may for instance be more appropriate if one wishes to explore individual dimensions of caregiving such as spousal burden 
or the subjective experience of the care received. However, if the relationship and relational dimensions are of interest to the study, conjoint interviews may be all the more fruitful.

\section{Acknowledgements}

The study on which this article is based is part of the research program Forms of Care in Later Life: Agency, Place, Time and Life Course, at the National Institute for the Study of Ageing and Later Life (NISAL), Linköping University, Sweden. The program was financed by FAS (now Forte, Swedish Research Council for Health, Working Life and Welfare, Dnr 2006-1621). The author would like to thank Kristian Gjessing for reading and commenting on previous drafts of this manuscript and for proofreading the final version.

\section{References}

Ahn, T. and Kim, K. (2007). Mutual caring of elderly Korean couples. Journal of Transcultural Nursing, 18 (1): 28-34

Allan, G. (1980). A note on interviewing spouses together. Journal of Marriage and the Family, 42 (1): 205-210

Arskey, H. (1996). Collecting data through joint interviews. Social Research Update, vol. 15. Available at http://sru.soc.surrey.ac.uk/SRU15.html (Accessed on 24/8/12)

Beitin, B.K. and Allen, K. (2005). Resilience in Arab-American couples after September 11, 2001: a systems perspective. Journal of Marital and Family Therapy, 31 (3): 251-268

Ben-Ari, A. and Lavee, Y. (2007). Dyadic closeness in marriage: from the inside story to a conceptual model. Journal of Social and Personal Relationships, 24 (5): 627-644

Bennett, L.A. and McAvity, K.J. (1994). Family research: a case for interviewing couples. In: G. Handel and G. Whitchurch (Eds.), The Psychosocial Interior of the Family. New York: Walter de Gruyter, pp. 87-107

Bjørnholt, M. and Farstad, G.R. (2012). 'Am I rambling?' On the advantages of interviewing couples together. Qualitative Research, 13 (3): Epub ahead of print 28 Sep 2012. DOI: 10.1177/1468794112459671

Braun, M., Scholz, U., Bailey, B., Perren, S., Hornung, R. and Martin, M. (2009). Dementia caregiving in spousal relationships: a dyadic perspective. Aging and Mental Health, 13 (3): 426-436

Cahill, E., Lewis, L.M., Barg, F.K. and Bogner, H.R. (2009). “You don't want to burden them": older adults' views on family involvement in care. Journal of Family Nursing, 15 (3): 295-317

Clipp, E.C. and George, L.K. (1992). Patients with cancer and their spouse caregivers. Perceptions of the illness experience. Cancer, 69 (4): 1074-1079

Eisikovits, Z. and Koren, C. (2010). Approaches to and outcomes of dyadic interview analysis. Qualitative Health Research, 20 (12): 1642-1655

Forbat, L. and Henderson, J. (2003). "Stuck in the middle with you": the ethics and process of qualitative research with two people in an intimate relationship". Qualitative Health Research, 13(10):1453-1462

Heaphy, B. and Einarsdottir, A. (2012). Scripting civil partnerships: interviewing couples together and apart. Qualitative Research, Epub ahead of print 22 Aug 2012. DOI: 10.1177/1468794112454997 
Hellström, I., Nolan, M. and Lundh, U. (2005a). Awareness context theory and the dynamics of dementia: improving understanding using emergent fit. Dementia, 4 (2): 269-295

Hellström, I., Nolan, M. and Lundh, U. (2005b). 'We do things together': a case study of 'couplehood' in dementia. Dementia, 4 (1): 7-22

Hydén, L-C. and Bülow, P.H. (2003). Who's talking: drawing conclusions from focus groups - some methodological considerations. International Journal of Social Research Methodology, 6 (4):305-321

Jeppsson Grassman, E., Whitaker, A. and Larsson, A.T. (2009). Family as failure? The role of informal help-givers to disabled people in Sweden. Scandinavian Journal of Disability Research, 11 (1): 35-49

Jo, S., Brazil, K., Lohfeld, L. and Willison, K. (2007). Caregiving at the end of life: perspectives from spousal caregivers and care recipients. Palliative and Supportive Care, 5 (1): 11-17

Keady, J. and Nolan, M. (2003). The dynamics of dementia: working together, working separately or working alone? In: M. Nolan, U. Lundh, J. Keady and G. Grant (Eds.) Partnerships in Family Care. Maidenhead, Berkshire: Open University Press, pp.15-32

Kenny, D.A., Kashy, D.A. and Cook, W.L. (2006). Dyadic Data Analysis. New York: Guilford

Kitzinger, J. (1994). The methodology of focus groups: the importance of interaction between research participants. Sociology of Health and Illness, 16 (1): 103-121

Kleinman, A. (1988). The Illness Narratives. Suffering, Healing and the Human Condition. New York: Basic Books

Kvale, S. and Brinkmann, S. (2009). InterViews: Learning the Craft of Qualitative Research interviewing. Thousand Oaks, CA: Sage

Mauthner, M. (2000). Snippets and silences: ethics and reflexivity in narratives of sistering. International Journal of Social Research Methodology, 3 (4): 287-306

McGovern, J. (2011). Couple meaning-making and dementia: challenges to the deficit model. Journal of Gerontological Social Work, 54 (7): 678-690

Molyneaux, V., Butchard, S., Simpson, J. and Murray, C. (2011). The co-construction of couplehood in dementia. Dementia, 11 (4): 483-502

Morgan, D.L. (1996). Focus groups. Annual Review of Sociology, 22 (1): 129-152

Morris, S.M. (2001). Joint and individual interviewing in the context of cancer. Qualitative Health Research, 11 (4): 553-567

Parker, G. (1993). With This Body: Caring and Disability in Marriage. Buckingham: Open University Press 
Racher, F.E. (2003). Using conjoint interviews to research the lived experience of elderly rural couples. Nurse Researcher, 10 (3): 60-72

Reissman, C.K. (1993). Narrative Analysis. Newbury Park, CA: Sage

Rosenblum, L.P. (2000). Perceptions of the impact of visual impairment on the lives of adolescents. Journal of Visual Impairment and Blindness, 94 (7): 434-45

Schumacher, K.L. (1996). Conceptualizing family caregiving: family-based illness care during chemotherapy. Research in Nursing and Health, 19 (4): 261-271

Seale, C., Charteris-Black, J., Dumelow, C., Lacock, L. and Ziebland, S. (2008). The effect of joint interviewing on the performance of gender. Field Methods, 20 (2): 107-128

Soodeen, R., Gregory, D. and Bond, J. (2007). Home care for older couples: "It feels like a security blanket...". Qualitative Health Research, 17 (9): 1245-1255

Taylor, B. and de Vocht, H. (2011). Interviewing separately or as couples? Considerations of authenticity of method. Qualitative Health Research, 21 (11): 1576-1587

Torgé, C.J. (2012). Ageing and care among disabled couples. In E. Jeppsson Grassman and A. Whitaker (Eds.), Ageing with Disability. Bristol: Policy Press, pp. 109-127

Thompson, L. and Walker, A.J. (1982). The dyad as the unit of analysis: conceptual and methodological issues. Journal of Marriage and the Family, 44 (4): 889-900

van Nes, F., Runge, U. and Jonsson, H. (2009). One body, three hands and two minds: a case study of the intertwined occupations of an older couple after a stroke. Journal of Occupational Science, 16 (3): 194-202

Walker, R.B. and Luszcz, M.A. (2009). The health and relationship dynamics of late-life couples: a systematic review of the literature. Ageing and Society, 29 (3): 455-480

Yorgason, J., Piercy, F. and Piercy, S. (2007). Acquired hearing impairment in older couple relationships: an exploration of couple resilience process. Journal of Aging Studies, 21 (3): 215-228

Yorgason, J., Roper, S.O., Wheeler, B., Crane, K., Byron, R., Carpenter, L., Sandberg, J.G., Sheffield, R. and Higley, D. (2010). Older couples' management of multiple-chronic illnesses: individual and shared perceptions and coping in type 2 diabetes and osteoarthritis. Families, Systems and Health, 28 (1): 30-47

\section{Author}

Cristina Joy Torgé is a PhD candidate at the National Institute for the Study of Ageing and Later Life (NISAL), in Linköping University, Sweden. Email: cristina.joy.torge@liu.se 